\title{
Insulin Glargine 300 Units/mL Effectiveness in Patients with T2DM Uncontrolled by Basal Insulin in Real-Life Settings in the Czech Republic
}

\author{
Martin Prázný1,2* (D), Milan Flekač ${ }^{1,2}$, Petr Jelínek ${ }^{3}$, Jana Mašková4 \\ ${ }^{1}$ Department of Internal Medicine, General Faculty Hospital, Prague, Czech Republic \\ ${ }^{2}$ Faculty of Medicine, Charles University, Prague, Czech Republic \\ ${ }^{3}$ Sanofi, Prague, Czech Republic \\ ${ }^{4}$ NEOX Clinical Research, Prague, Czech Republic \\ Email: *mpra@LF1.cuni.cz
}

How to cite this paper: Prázný, M., Flekač, M., Jelínek, P. and Mašková, J. (2020) Insulin Glargine 300 Units/mL Effectiveness in Patients with T2DM Uncontrolled by Basal Insulin in Real-Life Settings in the Czech Republic. Journal of Diabetes Mellitus, 10, 109-123.

https://doi.org/10.4236/jdm.2020.103010

Received: February 8, 2020

Accepted: June 20, 2020

Published: June 23, 2020

Copyright $\odot 2020$ by author(s) and Scientific Research Publishing Inc. This work is licensed under the Creative Commons Attribution International License (CC BY 4.0).

http://creativecommons.org/licenses/by/4.0/

\begin{abstract}
Introduction: To evaluate the clinical effectiveness of Gla-300 units/mL (Gla300 ) in the treatment of patients with type 2 diabetes (T2DM) uncontrolled by basal insulin in real-life clinical settings in the Czech Republic (TOPAZ study). Methods: TOPAZ was a prospective, multi-center, non-interventional, 6-month study. Of the 312 patients screened, 289 were evaluated at month 6 . The primary objective was the change of HbAlc after 6 months. The proportion of patients with $\mathrm{HbAlc}<7.0 \%$ DCCT $(<53 \mathrm{mmol} / \mathrm{mol})$, and those with a decrease of at least $0.5 \%$ of $\mathrm{HbAlc}$ at month 6 , change in FPG, body weight and insulin dose at month 3 and 6 were analysed as secondary objectives. Incidence of hypoglycemia, adverse events and patient treatment satisfaction were also assessed. Results: HbAlc decreased significantly after 6 months (mean change $0.9 \% \pm 1.1 \%$ DCCT $[-9.9 \pm 11.6 \mathrm{mmol} / \mathrm{mol}], \mathrm{p}<0.0001$ ). HbAlc target $<7.0 \%$ DCCT was achieved in $17.6 \%$ of patients, $66.1 \%$ of patients showed mean HbAlc decrease of $0.5 \% \pm 0.8 \%$. At month 6 , FPG decreased (mean change from baseline $-1.8 \pm 3.1 \mathrm{mmol} / \mathrm{L}$ ) as well as the incidence of hypoglycemia decreased by $49 \%(\mathrm{p}<0.0001)$ while no weight gain was observed. No significant safety signals were identified. Conclusion: In a real-life setting, switching to Gla-300 in T2DM patients uncontrolled with other basal insulin was associated with improved glycemic control and reduced risk of hypoglycemia without weight gain, while patients' satisfaction with treatment increased.
\end{abstract}




\section{Keywords}

Fasting Plasma Glucose, Glycated Hemoglobin, Hypoglycemia, Insulin Glargine (Gla-300 Units/Ml), Real Life Data, Type 2 Diabetes (T2DM)

\section{Introduction}

The incidence of diabetes is growing throughout the world, and this disease is a serious problem not only for patients themselves but for whole society. The global prevalence of T2DM has nearly doubled since 1980, rising from $4.7 \%$ to $8.5 \%$ in adults. This is influenced primarily by the overall lifestyle: particularly, by the increased number of obese individuals in the population [1] [2]. It is estimated that in 2040, 642 million people will suffer from diabetes worldwide [3] [4]. Lifestyle management (including medical nutrition therapy, physical activity, weight loss, counseling for smoking cessation) together with oral antihyperglycemic drugs (OADs) are fundamental aspects of diabetes care [5] [6] [7] [8]. The early introduction of basal insulin is well established, in particular when HbA1c levels are very high (>97 $\mathrm{mmol} / \mathrm{mol}[>11 \%])$, symptoms of hyperglycemia are present, or there is evidence of ongoing catabolism (e.g., weight loss) [7] [8].

International diabetes management organizations (American Diabetes Association $[\mathrm{ADA}]$ and European Association for the Study of Diabetes [EASD]) recommend basal insulin as the most efficient therapy in patients with insufficiently controlled diabetes by non-pharmacological treatment in combination with other antidiabetic drugs [7] [8]. Glycemic control is strictly defined by ADA and EASD as level of glycated hemoglobin HbAlc (NGSP) < 7.0\% [7] [8].

Insulin glargine $300 \mathrm{U} / \mathrm{mL}$ (Gla-300), a second-generation basal insulin analog, is approved for use in adult patients with T2DM who did not reach acceptable glycemic control with current antidiabetics and non-pharmacological treatment (diet and exercise) [9], in combination with OADs. Three phase III studies compared the efficacy and safety of Gla-300 with insulin glargine $100 \mathrm{U} / \mathrm{mL}$ (Gla-100) in different populations of patients with T2DM [10] [11] [12]. EDITION 1 included participants with T2DM not adequately controlled with basal and mealtime insulin [10], EDITION 2 included participants who had previously received basal insulin in combination with OADs [11]. In EDITION 3, participants were insulin-naive, and had received only OADs [12]. In these studies, testing insulin Gla-300 versus Gla-100, a comparable glycemic control was achieved, while the incidence of hypoglycemia was lower in patients treated with Gla-300 [10] [11] [12] [13]. Nevertheless, in RCTs, outcomes do not always mirror those seen in the real world and there is growing demand for real-world data to support decision-making [14].

Although insulin Gla-300 was approved at the end of 2015, only limited data are currently available to demonstrate its efficacy and safety in real-life clinical practice in the Czech Republic. 
The purpose of the present non-interventional study was to evaluate the effectiveness and safety of switching from another basal insulin to Gla-300 in patients with insufficiently controlled T2DM in real-life setting.

\section{Materials and Methods}

\subsection{Study Design, Participants and Outcomes}

TOPAZ was a prospective, multicenter, national, observational, single-arm, 6-month study to observe clinical effectiveness of Gla-300 in the treatment of T2DM patients insufficiently controlled by basal insulin in the Czech Republic. There were 312 patients screened and signed informed consent form between 25 May of 2016 and 27 September of 2017. This study was conducted in accordance with the principles laid down by the 18th World Medical Assembly [15], including all subsequent amendments and approved by appropriate ethical committees. The project was available to patients imminently planned for Gla-300 treatment as well as to patients where Gla-300 treatment was initiated $0-28$ days before enrollment. Inclusion criteria were diagnosed T2DM, age $\geq 18$ years, HbAlc $>$ $7.6 \%$ ( $>60 \mathrm{mmol} / \mathrm{mol}$ ) or repeated hypoglycemia during human basal insulin treatment, therapy with basal insulin with or without non-insulin antidiabetic drugs (for at least 3 months), signed informed consent form. Exclusion criteria were type 1 diabetes mellitus, patient receiving any prandial insulin, pregnancy and breastfeeding, current participation in interventional study, age $<18$ years and patients who could not attend all scheduled visits.

The primary endpoint was change in $\mathrm{HbAlc}$ between baseline and month 6 . The secondary endpoints were: percentage of patients with $\mathrm{HbA1c}<7.0 \%(<53$ $\mathrm{mmol} / \mathrm{mol}$ ), percentage of patients with a decrease of $\mathrm{HbAlc}$ from baseline to month 6 of at least $0.5 \%$, change in fasting plasma glucose from baseline to month 3 and month 6 , change in body weight from baseline to month 3 and month 6 , change in dose of Gla-300 from baseline to month 3 and month 6, hypoglycemia incidence (\% of participants with at least one or more hypoglycemia events: symptomatic, symptomatic confirmed with plasma glucose $\leq 3.9 \mathrm{mmol} / \mathrm{L}$, severe and nocturnal) and standardized event rate (calculated as number of events per patient-year), occurrence of adverse events (AEs) and serious adverse events (SAEs) during the duration of the study, and patient's treatment satisfaction (DTSQ) [16].

\subsection{Data Collection}

Following parameters were recorded at baseline: demography, age, gender, body height and weight, initial diagnosis, occurrence of diabetes complications, personal and medication history, changes in concomitant therapy at the time of Gla-300 initiation, previous and current antidiabetic therapy (OADs and insulins), level of $\mathrm{HbAlc}$ and fasting glycaemia (as close as possible at time before enrollment/at enrollment/before initiation of Gla-300 therapy), level of alanine aminotransferase (ALT), aspartate aminotransferase (AST), low-density lipoprotein (LDL) cholesterol, creatinine, values of fasting self-monitored blood glucose (SMBG) (last 3 available measurements), physician decision to initiate Gla-300, 
Gla-300 therapy (total daily dose, time and date of therapy initiation), target FPG, recommendation of Gla-300 dose titration, hypoglycemia during 3 months before enrolment and diabetes treatment satisfaction questionnaire.

Following parameters were recorded at months 3 and 6: body weight, current antidiabetic therapy, current Gla-300 therapy, other concurrent therapy, HbA1c, fasting glycaemia, prebreakfast SMBG values (the last 3 available measurements), occurrence of hypoglycemia since the previous visit (self-reported), occurrence of adverse events since the previous visit, DTSQ at month 6. AEs and SAEs were collected during the whole study.

\subsection{Statistics}

Analysis of collected data was based on descriptive statistics, including absolute and relative frequencies of discrete variables. Continuous variables were described by count (without missing data), mean, and standard deviation, median, minimum, and maximum. Discrete variables were described by count (absolute frequency), and percentages (relative frequency). All statistical analyses were performed at the 2 -sided $5 \%$ significance level or 2 -sided $95 \%$ confidence intervals (CI). Null hypothesis, that the change in $\mathrm{HbAlc}$ from baseline to month 6 is equal to 0 , was analysed by a non-parametric Wilcoxon signed-rank test, as data were not normally distributed (confirmed by Shapiro-Wilk test). Hypoglycemia event rate was calculated for each visit. As the data were not normally distributed (confirmed by Shapiro-Wilk test), the null hypothesis, that there is no difference in hypoglycemia rate in the period before baseline, before visit at month 3 and before month 6, was analysed by non-parametric Friedman test for dependent repeated measures. The data missing for each analysis were then accounted for. No imputation of missing data was performed. With assumed sample size of 259 patients, and expected 15\% drop-out, it was planned to enroll total of 312 patients in the study, to obtain sufficient data to enable $90 \%$ power of analysis to yield a statistically significant result.

In this study, 2 analysis populations were defined: the full analysis set (FAS, $\mathrm{n}$ $=300)$, and Safety Population $(\mathrm{n}=312)$. FAS included all eligible subjects, who had to meet all inclusion and no exclusion criteria and who should have taken at least one dose of Gla-300. If a patient was incorrectly included in the study, he/she was excluded from FAS according to ICH E9 Guideline [17]. The Safety Population consisted of patients who have signed an informed consent form and who have taken at least one dose of Gla-300. Safety population was used for evaluation of the incidence of hypoglycemia, occurrence of AEs and SAEs, and DTSQ questionnaires. No interim analyses were performed.

\section{Results}

Overall, of the 312 patients who were screened and signed informed consent form between 25 May of 2016 and 27 September of 2017 at 55 sites, 23 patients were prematurely withdrawn from the study. Therefore, 300 evaluable patients were available for analysis at baseline, 296 patients at month 3 and 289 patients at month 6 . 


\subsection{Baseline Patients' Characteristics}

Out of 300 patients, $56.3 \%$ (169/300) were men and 43.7\% (131/300) were women. The average age of patients in TOPAZ study was $63.4 \pm 9.0$ years. Baseline patients' characteristics are summarized in Table 1 . Basal insulins received before

Table 1. Baseline patients' characteristics.

\begin{tabular}{|c|c|c|c|c|c|}
\hline Baseline characteristics & $\mathbf{n}$ & $\%$ & Mean \pm SD & $95 \% \mathrm{CI}$ & Median \\
\hline Age (years) & 300 & & $63.4 \pm 9.0$ & $62.4-64.4$ & 64.0 \\
\hline Men & 169 & 56.3 & & & \\
\hline Women & 131 & 43.7 & & & \\
\hline Body weight $(\mathrm{kg})$ & 300 & & $96.1 \pm 17.6$ & $93.1-98.1$ & 95.0 \\
\hline $\operatorname{BMI}\left(\mathrm{kg} / \mathrm{m}^{2}\right)$ & 299 & & $32.7 \pm 5.4$ & $32.1-33.3$ & 31.8. \\
\hline Systolic BP (mm Hg) & 300 & & $137.3 \pm 15.1$ & $135.6-139.0$ & 136.0 \\
\hline Diastolic BP (mm Hg) & 300 & & $74.0 \pm 9.5$ & $77.9-80.1$ & 80.0 \\
\hline $\mathrm{HbA} 1_{\mathrm{c}}(\mathrm{mmol} / \mathrm{mol})$ & 300 & & $72.4 \pm 10.3$ & $71.2-73.5$ & 69.5 \\
\hline $\mathrm{HbAl}_{\mathrm{c}}(\% \mathrm{DCCT})$ & 300 & & $8.8 \pm 0.9$ & $8.7-8.9$ & 8.5 \\
\hline $\mathrm{FPG}(\mathrm{mmol} / \mathrm{L})$ & 300 & & $9.3 \pm 2.8$ & $8.9-9.6$ & 8.9 \\
\hline Creatinine $(\mu \mathrm{mol} / \mathrm{L})$ & 265 & & $84.6 \pm 21.6$ & NA & 83.0 \\
\hline \multicolumn{6}{|l|}{ Duration of diabetes } \\
\hline$<5$ years & 65 & 22 & & & \\
\hline $5-10$ years & 79 & 26 & & & \\
\hline$>10$ years & 156 & 52 & & & \\
\hline $\begin{array}{l}\text { Initial dose of insulin } \\
\text { glargine } 300 \mathrm{U} / \mathrm{mL}\end{array}$ & 300 & & $27.1 \pm 12.2$ & $25.7-28.5$ & 24.0 \\
\hline
\end{tabular}

\section{OAD treatment}

$\begin{array}{ccc}\text { metformin } & 249 & 83 \\ \text { sulfonylurea } & 129 & 43 \\ \text { pioglitazone } & 13 & 4 \\ \text { DPP-4 inhibitors } & 102 & 34 \\ \text { glinides } & 9 & 3 \\ \alpha \text {-glucosidase inhibitors } & 297 & 99 \\ \text { SGLT2 inhibitors } & 37 & 12 \\ \text { GLP1 receptor agonists } & 21 & 7\end{array}$

BMI: Body Mass Index, BP: Blood Pressure, HbAlc: Glycated Hemoglobin, FPG: Fasting Plasma Glucose, SD: Standard Deviation, CI: Confidence Interval, DPP-4: Dipeptidyl peptidase 4, OAD: Oral Antidiabetic Drug, SGLT2: Sodium Glucose Linked Transporter 2, GLP1: Glucagon-like Peptide 1. 
initiation of Gla-300 were mainly Gla-100 (45\%), NPH (27\%), and insulin detemir (28\%) (supplementary Table S1). The most frequent complications of diabetes were: neuropathy in 75 (25\%) of patients, followed by nephropathy in 53 (18\%), retinopathy in $49(16 \%)$, diabetic foot syndrome in 7 (2\%) and amputation of the lower limb in $1(0.3 \%)$ of patients. Patients reported following comorbidities: hypertension in 265 (88\%), dyslipidemia in 248 (83\%), ischemic heart disease in 61 (20\%), hypothyroidism in 36 (12\%), myocardial infarction in $29(10 \%)$, lower extremity peripheral artery disease in $24(8 \%)$, heart failure in $16(5 \%)$, stroke in $12(4 \%)$, transient ischemic attack in $10(3 \%)$ and hyperthyroidism in $1(0.3 \%)$ patient.

\subsection{Effectiveness of Gla-300 Treatment}

Mean HbAlc was $8.8 \pm 0.9 \%(72.4 \pm 10.3 \mathrm{mmol} / \mathrm{mol})$ at baseline and $7.9 \% \pm$ $1.1 \%(62.5 \pm 11.8) \mathrm{mmol} / \mathrm{mol}$ after 6 months of Gla-300 treatment (Table 2).

Table 2. Summary of key efficacy parameters and the daily dose of Gla-300 U/mL in U/day and in U/kg/day. Table includes descriptive statistics for HbAlc in the whole cohort of patients at baseline and at month 6 and for Fasting Plasma Glucose at baseline and months 3 and 6 . HbAlc was also analyzed for subgroups of patients reaching HbAlc below and above $53 \mathrm{mmol} / \mathrm{mol}(7 \%)$ and with $\mathrm{HbAlc}$ decrease of more and less than $0.5 \%$.

\begin{tabular}{|c|c|c|c|c|c|c|}
\hline Variable & n (\%) & Mean \pm SD & $95 \% \mathrm{CI}$ & Min & $\operatorname{Max}$ & Median \\
\hline $\mathrm{HbA} 1_{c}$ at baseline $(\mathrm{mmol} / \mathrm{mol})$ & $300(100 \%)$ & $72.4 \pm 10.3$ & $71.2-73.5$ & 61.0 & 121.0 & 69.5 \\
\hline $\mathrm{HbA} 1_{\mathrm{c}}$ at month $6(\mathrm{mmol} / \mathrm{mol})^{*}$ & $289(96.3 \%)$ & $62.5 \pm 11.8$ & $61.1-63.9$ & 30.0 & 115.0 & 60.0 \\
\hline $\mathrm{HbAl}_{\mathrm{c}}$ at month $6(\% \mathrm{DCCT})^{*}$ & $289(96.3 \%)$ & $7.9 \pm 1.1$ & $7.7-8.0$ & 4.9 & 12.7 & 7.6 \\
\hline $\mathrm{HbA} 1_{\mathrm{c}}<53 \mathrm{mmol} / \mathrm{mol}$ at month 6 & $51(17.6 \%)$ & $49.1 \pm 3.7$ & $48.1-50.2$ & 30.0 & 52.0 & 50.0 \\
\hline $\mathrm{HbA} 1_{\mathrm{c}} \geq 53 \mathrm{mmol} / \mathrm{mol}$ at month 6 & $238(82.4 \%)$ & $65.4 \pm 11.0$ & $64.0-66.8$ & 53.0 & 115.0 & 62.0 \\
\hline $\mathrm{HbAl}_{\mathrm{c}}<7 \%$ at month 6 & $51(17.6 \%)$ & $6.7 \pm 0.3$ & $6.6-6.7$ & 4.9 & 6.9 & 6.7 \\
\hline $\mathrm{HbA}_{\mathrm{c}} \geq 7 \%$ at month 6 & $238(82.4 \%)$ & $8.1 \pm 1.0$ & $8.0-8.3$ & 7.0 & 12.7 & 7.8 \\
\hline $\mathrm{HbA} 1_{c}$ decrease of less than $0.5 \%$ at month 6 & $98(33.9 \%)$ & $8.7 \pm 1.1$ & $8.5-8.9$ & 7.4 & 12.1 & 8.5 \\
\hline FPG at baseline $(\mathrm{mmol} / \mathrm{L})$ & $300(100 \%)$ & $9.3 \pm 2.8$ & $8.9-9.6$ & 3.0 & 22.4 & 8.9 \\
\hline FPG at month $3(\mathrm{mmol} / \mathrm{L})$ & $295(98.3 \%)$ & $7.8 \pm 2.3$ & $7.5-8.1$ & 3.8 & 20.1 & 7.3 \\
\hline FPG at month $6(\mathrm{mmol} / \mathrm{L})$ & $289(96.3 \%)$ & $7.5 \pm 2.1$ & $7.3-7.8$ & 3.9 & 15.7 & 7.1 \\
\hline Dose of Gla-300 at baseline (U/day) & $300(100 \%)$ & $27.1 \pm 12.2$ & $25.7-28.5$ & 8 & 80 & 24.0 \\
\hline Dose of Gla-300 at month 3 (U/day) & $295(98.3 \%)$ & $30.9 \pm 12.9$ & $29.4-32.4$ & 8 & 84 & 28.0 \\
\hline Dose of Gla-300 at month 6 (U/day) & $289(96.3 \%)$ & $33.7 \pm 13.8$ & $32.1-35.3$ & 8 & 80 & 32.0 \\
\hline Dose of Gla-300 at baseline (U/kg/day) & $300(100 \%)$ & $0.29 \pm 0.12$ & $0.27-0.30$ & 0.07 & 0.82 & 0.27 \\
\hline Dose of Gla-300 at month 6 (U/kg/day) & $289(96.3 \%)$ & $0.36 \pm 0.14$ & $0.34-0.37$ & 0.08 & 0.91 & 0.34 \\
\hline
\end{tabular}

${ }^{*}$ Statistically significant change of HbAlc from baseline ( $<$ 0.0001); FPG analysis was exploratory HbA1c Glycated Hemoglobin, FPG: Fasting Plasma Glucose, SD: Standard Deviation, CI: Confidence Interval. 
This decrease of HbA1c (mean change $-0.9 \% \pm 1.06 \%(-9.9 \pm 11.6 \mathrm{mmol} / \mathrm{mol}$ ) was statistically significant ( $\mathrm{p}<0.0001$ ). After 6 months of treatment with Gla-300, $17.6 \%(51 / 289)$ of patients uncontrolled on previous basal insulin achieved HbA1c target $<7.0 \%$ DCCT $(<53 \mathrm{mmol} / \mathrm{mol}$ ) (Table 2). Mean HbA1c change from baseline to month 6 in patients with $\mathrm{HbA1c}<7.0 \%$ was more than double the $\mathrm{HbA} 1 \mathrm{c}$ change in patients with $\mathrm{HbA1c} \geq 7.0 \%(-1.77 \% \pm 0.9 \%$ versus $-0.72 \% \pm$ $1.0 \%)$. Decrease in HbA1c from baseline to month 6 of at least $0.5 \%$ was detected in $66.1 \%(191 / 289)$ of patients (Table 2). In this group of patients, mean HbA1c change was $-1.47 \% \pm 0.8 \%$, while in the second group of patients with $\mathrm{HbA} 1 \mathrm{c}$ change below $0.5 \%$, the mean HbA1c change was $+0.2 \% \pm 0.6 \%$.

FPG decreased after 3 months of Gla-300 treatment (mean change from baseline $-1.5 \pm 3.0 \mathrm{mmol} / \mathrm{L}$ ) and persisted to month 6 (mean change from baseline $-1.8 \pm 3.1 \mathrm{mmol} / \mathrm{L}$ ) as described in Table 2. Body weight was stable during the whole study, mean weight change from baseline to month 6 was $0.09 \pm 4.1 \mathrm{~kg}$. During insulin titration in the study, the mean daily dose of Gla-300 increased from $27.1 \pm 12.2 \mathrm{U}$ at baseline to $30.9 \pm 12.9 \mathrm{U}$ at month 3 and to $33.7 \pm 13.8 \mathrm{U}$ at month 6 (Table 2 and supplementary Figure S1). Mean change of daily dose from baseline to month 3 was $3.7 \pm 5.8 \mathrm{U}$ and from baseline to month 6 was $6.6 \pm 6.5 \mathrm{U}$.

Analysis of hypoglycemia occurrence was performed in the Safety Population ( $\mathrm{n}$ = 312). Hypoglycemia occurrence decreased by half after Gla-300 therapy initiation as shown in Figure 1. The lowest hypoglycemia occurrence was observed in period between baseline and month 3 in all hypoglycemia categories. Although patients had reported hypoglycemia more frequently during the period between month 3 and month 6, hypoglycemia occurrence in all assessed categories did not reach the level observed at baseline. Differences among the mean ranks of hypoglycemia event rate that were 2.10 before baseline, 1.93 before visit at month 3 and 1.98 before visit at month 6 was statistically significant $(\mathrm{p}<0.001)$ as confirmed by Friedman test.

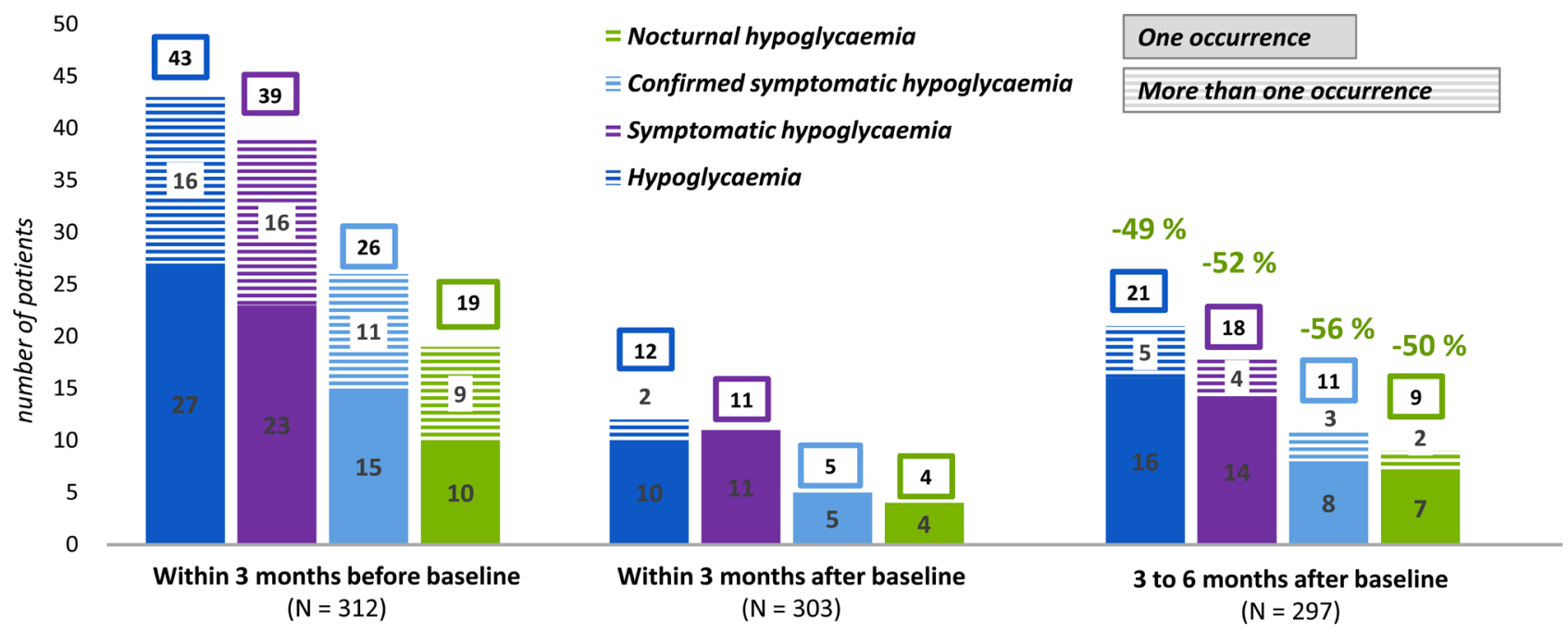

Figure 1. Hypoglycemia occurrence. Four hypoglycemia categories were evaluated separately. Each column represents the total number of hypoglycemia and ratio of cases of just one occurrence (full part of columns) and the number of cases with more than one hypoglycaemia event (hatched part of column). Moreover, in month 6, percentage change from baseline is presented directly in the figures. 
Patients' satisfaction increased after Gla-300 treatment initiation, as assessed by Total Treatment Satisfaction Scale in DTSQ. Patients rated their satisfaction by $23.7 \pm 7.5$ points (mean) in Total Status Scale at baseline, by $28.5 \pm 5.4$ points (mean) at month 6, and the mean change (all means) between month 6 and baseline was $11.1 \pm 5.3$ points $(\mathrm{p}<0.0001)$. Figure 2 shows responses to individual DTSQ questions at baseline and after 6 months of Gla-300 treatment.

\subsection{Safety of Gla-300 Treatment}

Overall, 8 AEs (acute gastroenteritis, venous ulcer, worsening of T2DM control, cold, carpal tunnel surgery, microbial eczema, insufficient effect of Gla-300, minor brain ischemia) and 6 SAEs (basalioma, stroke, hernia in scar, embolism and thrombosis of lower limb artery, atrial fibrillation, subacute MI) were reported during the study in 13 patients. One patient experienced 2 SAEs, therefore no AE/SAE was observed in $95.7 \%$ (287/300) of study participants. Out of all 14 AEs observed, 6 (42.9\%) were of mild intensity, 6 (42.9\%) were moderate and 2 (14.3\%) were severe. Investigators suspected Gla-300 to be related with 2 AEs (worsening of diabetes control and insufficient effect of Gla-300). These 2 AEs and 1 SAE (stroke) resulted in premature treatment discontinuation.

\section{DTSQs}

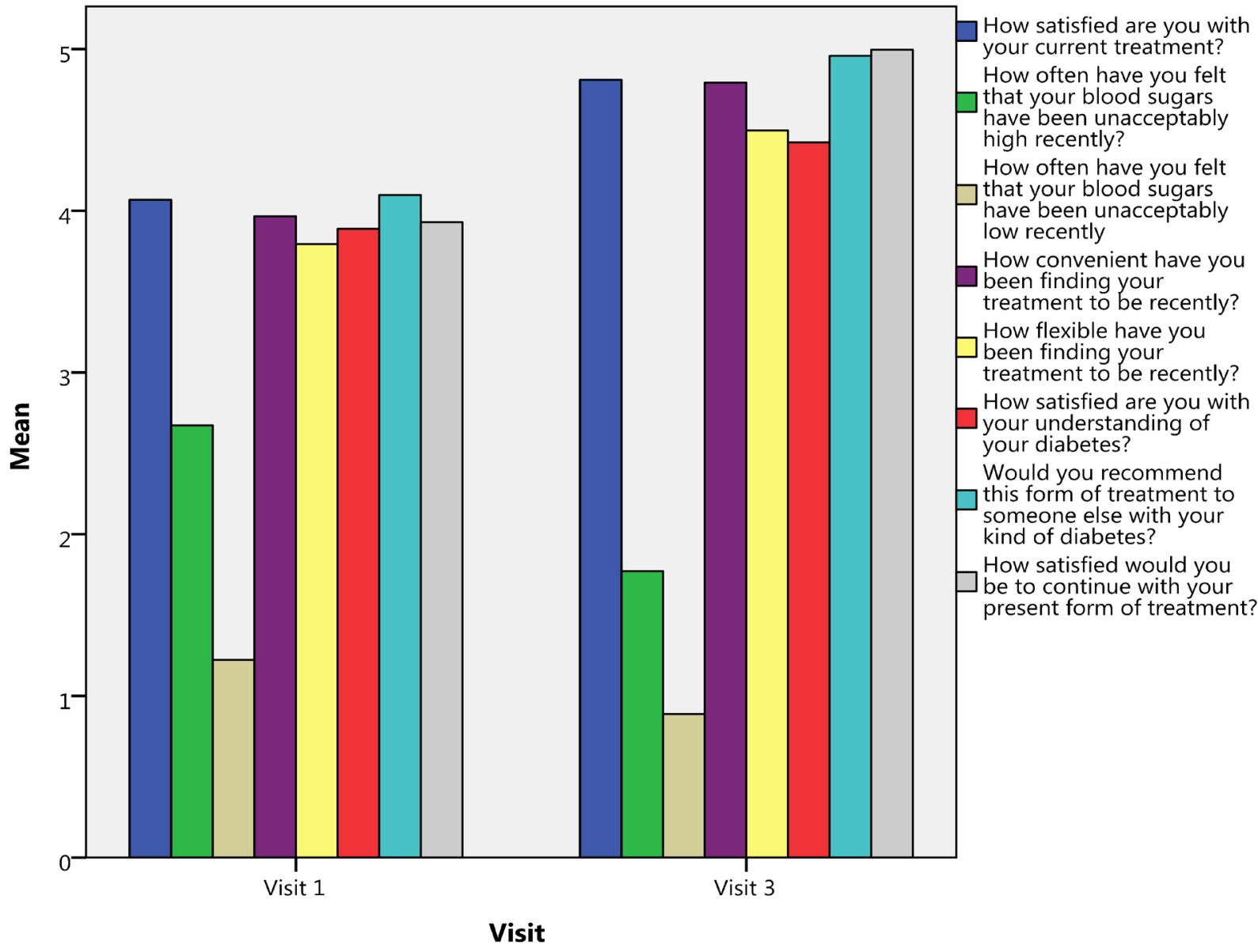

Figure 2. Patients' satisfaction with treatment (means for DTSQs questions) at baseline and at month 6. 


\section{Discussion}

Real-world studies provide information that is complementary to randomized clinical trials (RCTs) and may be more generalizable and pertinent to clinicians and healthcare-delivery systems [18]. The present study was designed to comprehensively describe the use of Gla-300 in the management of T2DM in real-life conditions in Czech Republic. The primary objective of the study was to evaluate the effectiveness and safety of switching to Gla-300 from any other basal insulin over a 6 months observational period in T2DM patients.

In this study, Gla-300 (Toujeo ${ }^{\circledR}$ ) treatment in real-life settings was associated with outcomes comparable with those reported from phase III clinical trials program EDITION [10] [11] [12]. Decrease of HbA1c after 6-month treatment was statistically significant. After 6 months of treatment with Gla-300, 17.6\% of patients uncontrolled on previous basal insulin achieved HbAlc target $<7.0 \%$ DCCT $(<53 \mathrm{mmol} / \mathrm{mol})$. Furthermore, two thirds of patients benefited from substantial mean $\mathrm{HbAlc}$ decrease. This was a subgroup of patients in whom HbA1c level decreased more than $0.5 \%$ during 6 -month treatment. In patients who reached the ADA and EASD (7) recommended level of $\mathrm{HbAlc}<7.0 \%$ at month 6 , we observed more than double the HbA1c change in comparison to those with $\mathrm{HbAlc} \geq 7.0 \%$. Other clinical parameters showed favorable profile during 6-month Gla-300 treatment.

Study objectives and population similar to those in the TOPAZ study were previously evaluated in clinical trial EDITION 2, which compared the efficacy and safety of Gla-300 with Gla-100) in people with T2DM, using basal insulin ( $\geq 42$ units/day) plus oral antihyperglycemic drugs [11]. In the EDITION 2 study, the authors reported $\mathrm{HbAlc}$ decrease in patients treated by Gla-300. Except for the concept of clinical trial versus real-world non-interventional study, EDITION 2 differs from TOPAZ study in baseline HbAlc level (means) $8.24 \%$ (66.6 mmol/mol) versus $8.8 \%(72.4 \mathrm{mmol} / \mathrm{mol})$, and in the population of patients with and without oral antihyperglycemics. In the meta-analysis of three Gla-300 clinical trials EDITION 1 - 3, published by Ritzel [19], HbA1c change (mean) from baseline to month 6 in insulin Gla-300 group was similar to the TOPAZ result. Conversely, the proportion of participants who reached target $\mathrm{HbAlc}<7.0 \%(<53 \mathrm{mmol} / \mathrm{mol})$ was much higher in EDITION 2 (30.6\%) and in meta-analysis (36.2\%) performed by Ritzel [19] than in the TOPAZ study (17.6\%). Lower target HbAlc attainment in the TOPAZ study may be caused by higher baseline HbAlc level, as TOPAZ inclusion criteria demanded $\mathrm{HbAlc}>7.6 \%(60 \mathrm{mmol} / \mathrm{mol})$ or repeated hypoglycemia during human basal insulin treatment. Also, dose optimization may not be the same in real-life than in treat-to-target studies, but other factors could be also relevant. The other clinical parameters were similar in EDITION 2 [11], meta-analysis [19] and TOPAZ study after 6-month of Gla-300 treatment: improvement of fasting plasma glucose and no weight gain.

Moreover, meta-analysis of three EDITION clinical trials after 12 months of Gla-300 treatment has recently been published by Ritzel [20], where mean HbAlc change from baseline to month 12 was $-0.91 \%(-9.95 \mathrm{mmol} / \mathrm{mol})$. Although the 
dose of Gla-300 after 12 months of treatment slightly increased, clinical benefits, including lowering risk of hypoglycemia and favorable safety profile of Gla-300 treatment were sustained in a broad population of people with T2DM over 12 months [20].

Recently, Zhou et al. (2018) published results of a retrospective cohort study comparing the real-world clinical and healthcare-resource utilization (HCRU) data in patients with type 2 diabetes using basal insulin (BI) who switched to Gla-300 or another BI [14]. They reported significant decrease of HbAlc during 6 months of insulin treatment, and the decrease was similar in both matched cohorts (Gla-300 and BI). Significantly fewer patients using Gla-300 experienced hypoglycemia compared to those using other BIs. Patients switching to Gla-300 had a significantly lower incidence of HCRU related to hypoglycemia. All-cause and diabetes-related hospitalization and emergency department HCRU were also favorable for Gla-300. These results are consistent with those observed in the TOPAZ study, except for HCRU, which was not evaluated in TOPAZ [14]. The observation of the lowest hypoglycemia occurrence with Gla-300 versus another basal insulin in period between baseline and month 3 , therefore after the insulin switch, is in accord with BRIGHT study, by Rosenstock recently published first head-to-head randomized controlled trial, comparing Gla-300 and insulin degludec, which showed lower hypoglycemia incidence in favor of Gla-300 during the titration period [21].

According to Gla-300 (Toujeo ${ }^{\circledR}$ ) Summary of Product Characteristics, as for all insulins, hypoglycemia is a common side effect [9]. Results from clinical trials demonstrated that the incidence of confirmed hypoglycemia was lower in patients treated with Gla-300, compared to Gla-100, in patients with type 2 diabetes treated in combination with either a non-insulin anti-hyperglycemic medicinal product (18\% risk reduction) or mealtime insulin (21\% risk reduction) [11]. The occurrence of hypoglycemia in the TOPAZ study decreased during Gla-300 treatment in comparison to the baseline level, and lower hypoglycemia occurrence persisted during the whole observed period to the end of the study.

The incidence of AEs/SAEs during Gla-300 treatment in the TOPAZ study was low: 8 AEs (2.6\% of patients) and 6 SAEs (2.0\% of patients) were reported during the study, 3 patients (1.0\%) discontinued Gla-300 treatment prematurely because of AE/SAE, and 2 AEs (0.6\%) were related to Gla-300 treatment according to physician judgement. In meta-analysis of all Gla-300 clinical trials [19], the following AEs/SAEs frequencies were reported: 57.3\% AEs and 5.2\% SAEs in total and $1.4 \%$ patients were withdrawn from the study due to AEs/SAEs. In the EDITION 2 study [11], 1.7\% AEs were related to the study treatment. In the TOPAZ study, participating physicians were obliged to record all the adverse events on every visit, as described in the protocol. However, diabetes care in the Czech Republic is performed almost exclusively by specialists in diabetology and not by general practitioners, who are usually much better informed about all patients' comorbidities, and who coordinate healthcare provided to a patient by other specialists. In a meta-analysis published by Ritzel [19], the most common AEs 
were: nervous system disorders, gastrointestinal disorders, musculoskeletal and connective tissue disorders, general disorders and administration site conditions. These AEs were different from those we observed in our study. Only two AEs related to Gla-300 treatment in the TOPAZ study were associated with diabetes (worsening of diabetes control and insufficient treatment efficiency). Overall, no new, or major safety signals were observed during treatment in TOPAZ study. High patient satisfaction assessed by DTSQ was reported in the TOPAZ study and in both Gla-300 and Gla-100 patient groups of the EDITION 2 study [11].

It is widely accepted that observational studies may play an important role in providing real-life outcomes, particularly in large cohorts with complex chronic diseases such as diabetes mellitus. Besides the strength of the dataset, the prospective collection of presented data on effectiveness and safety of Gla-300 there are some limitations to the current analysis deserving consideration. In the observational uncontrolled study design, we can't distinguish between the specific effects of the treatment and non-specific effects associated with the enrollment into the study. We thus do not suggest any causality between the observed effects and the switch to glargine $300 \mathrm{U} / \mathrm{mL}$. Our findings should be exclusively understood as the association between the study outcomes and initial insulin switch. Another study limitation may be represented by probable underreporting AEs including hypoglycemia by physicians specialized in diabetes care, and patients not discussing their health conditions other than associated with diabetes with investigators. In the Czech Republic, health conditions reported as AEs in the Gla-300 clinical trials [19] and general disorders are typically discussed with general practitioners or physicians with other specialties.

The strength of the TOPAZ study was that most of the endpoints were objective clinical laboratory values (HbA1c, FPG), or parameters (weight, dose). Furthermore, the number of enrolled patients was sufficient to enable $90 \%$ power of analysis to yield a statistically significant result.

\section{Conclusion}

In conclusion, in 300 Czech patients with T2DM uncontrolled by another basal insulin, switching to the second-generation basal insulin analogue glargine 300 $\mathrm{U} / \mathrm{mL}$ was associated with statistically and clinically significant $\mathrm{HbA1c}$ reduction, less hypoglycemia, no weight change and increased patients' satisfaction. Our results suggest that beneficial effects of Gla-300 shown in randomized controlled trials may be observed also in real-life settings.

\section{Acknowledgements}

The authors thank the participating physicians for their cooperation in the project. The authors received writing/editorial support in the preparation of this manuscript which was provided by Jaroslav Černý, MD, PhD, of AIXIAL s.r.o., and was funded by Sanofi Prague, Czech Republic. All authors had full access to all of the data in this study and take complete responsibility for the integrity of the data and accuracy of the data analysis. All named authors meet the Interna- 
tional Committee of Medical Journal Editors (ICMJE) criteria for authorship for this article, take responsibility for the integrity of the work as a whole, and have given their approval for this version to be published.

\section{Conflicts of Interest}

M.P. has served as consultant for Abbott, AstraZeneca, Boehringer Ingelheim, Dexcom, Eli Lilly, Medtronic, Novo Nordisk, Roche, Sanofi, and Takeda and is on Speakers Bureaus for Abbott, Boehringer Ingelheim, Dexcom, Eli Lilly, Medtronic, Novartis, Novo Nordisk, Roche, Sanofi and Teva. P.J. is employee and stockholder of Sanofi. J.M. is an employee of NEOX Clinical Research-clinical research organization that provided the following services funded by the sponsor: data management, statistical analyses and medical writing.

\section{Compliance with Ethics Guidelines}

All procedures performed in studies involving human participants were in accordance with the ethical standards of the institutional and/or national research committee and with the 1964 Helsinki declaration ant its later amendments or comparable ethical standards. Informed consent was obtained from all individual participants included in the study.

\section{Author's Contribution}

M.P. undertook main study supervision, participated in study design, discussed the data and their interpretation, participated in writing, editing and critical review of the manuscript the manuscript; and gave final approval of the manuscript. M.F. participated in study design, conducted the clinical trial and collected data, reviewed, edited and revised manuscript drafts; and gave final approval of the manuscript. P.J. participated in study design, participated on data acquisition, reviewed, edited and revised manuscript drafts; and gave final approval of the manuscript. J.M. participated on data acquisition, discussed the data and their interpretation, reviewed, edited and revised manuscript drafts; and gave final approval of the manuscript.

\section{References}

[1] Chatterjee, S., Khunti, K. and Davies, M.J. (2017) Type 2 Diabetes. The Lancet (London, England), 389, 2239-2251. https://doi.org/10.1016/S0140-6736(17)30058-2

[2] Collaboration NRF (2016) Worldwide Trends in Diabetes since 1980: A Pooled Analysis of 751 Population-Based Studies with 4.4 Million Participants. The Lancet (London, England), 387, 1513-1530.

[3] Ogurtsova, K., da Rocha Fernandes, J.D., Huang, Y., Linnenkamp, U., Guariguata, L., Cho, N.H., et al. (2016) IDF Diabetes Atlas: Global Estimates for the Prevalence of Diabetes for 2015 and 2040. Diabetes Research and Clinical Practice, 128, 40-50. https://doi.org/10.1016/j.diabres.2017.03.024

[4] Trikkalinou, A., Papazafiropoulou, A.K. and Melidonis, A. (2017) Type 2 Diabetes and Quality of Life. World Journal of Diabetes, 8, 120-129.

https://doi.org/10.4239/wjd.v8.i4.120 
[5] Mosenzon, O., Pollack, R. and Raz, I. (2016) Treatment of Type 2 Diabetes: From "Guidelines" to "Position Statements" and Back: Recommendations of the Israel National Diabetes Council. Diabetes Care, 39, S146-S153.

https://doi.org/10.2337/dcS15-3003

[6] Chamberlain, J.J., Herman, W.H., Leal, S., Rhinehart, A.S., Shubrook, J.H., Skolnik, N., et al. (2017) Pharmacologic Therapy for Type 2 Diabetes: Synopsis of the 2017 American Diabetes Association Standards of Medical Care in Diabetes. Annals of Internal Medicine, 166, 572-578. https://doi.org/10.7326/M16-2937

[7] Davies, M.J., D’Alessio, D.A., Fradkin, J., Kernan, W.N., Mathieu, C., Mingrone, G., et al. (2018) Management of Hyperglycaemia in Type 2 Diabetes, 2018. A Consensus Report by the American Diabetes Association (ADA) and the European Association for the Study of Diabetes (EASD). Diabetologia, 61, 2461-2498. https://doi.org/10.1007/s00125-018-4729-5

[8] Buse, J.B., Wexler, D.J., Tsapas, A., Rossing, P., Mingrone, G., Mathieu, C., et al. (2019) Update to: Management of Hyperglycemia in Type 2 Diabetes, 2018. A Consensus Report by the American Diabetes Association (ADA) and the European Association for the Study of Diabetes (EASD). Diabetes Care, 43, 487. https://doi.org/10.2337/dci19-0066

[9] Sanofi. Toujeo: Summary of Product Characteristics. https://www.ema.europa.eu/en/documents/product-information/toujeo-epar-produ ct-information_en.pdf

[10] Riddle, M.C., Bolli, G.B., Ziemen, M., Muehlen-Bartmer, I., Bizet, F. and Home, P.D. (2014) New Insulin Glargine 300 Units/mL versus Glargine 100 Units/mL in People with Type 2 Diabetes Using Basal and Mealtime Insulin: Glucose Control and Hypoglycemia in a 6-Month Randomized Controlled Trial (EDITION 1). Diabetes Care, 37, 2755-2762. https://doi.org/10.2337/dc14-0991

[11] Yki-Jarvinen, H., Bergenstal, R., Ziemen, M., Wardecki, M., Muehlen-Bartmer, I., Boelle, E., et al. (2014) New Insulin Glargine 300 Units/mL versus Glargine 100 Units/mL in People with Type 2 Diabetes Using Oral Agents and Basal Insulin: Glucose Control and Hypoglycemia in a 6-Month Randomized Controlled Trial (EDITION 2). Diabetes Care, 37, 3235-3243. https://doi.org/10.2337/dc14-0990

[12] Bolli, G.B., Riddle, M.C., Bergenstal, R.M., Ziemen, M., Sestakauskas, K., Goyeau, H., et al. (2015) New Insulin Glargine $300 \mathrm{U} / \mathrm{ml}$ Compared with Glargine $100 \mathrm{U} / \mathrm{ml}$ in Insulin-Naive People with Type 2 Diabetes on Oral Glucose-Lowering Drugs: A Randomized Controlled Trial (EDITION 3). Diabetes, Obesity \& Metabolism, 17, 386-394. https://doi.org/10.1111/dom.12438

[13] Becker, R.H., Dahmen, R., Bergmann, K., Lehmann, A., Jax, T. and Heise, T. (2015) New Insulin Glargine 300 Units $\mathrm{ml}^{-1}$ Provides a More Even Activity Profile and Prolonged Glycemic Control at Steady State Compared with Insulin Glargine 100 Units $\mathrm{ml}^{-1}$. Diabetes Care, 38, 637-643. https://doi.org/10.2337/dc14-0006

[14] Zhou, F.L., Ye, F., Berhanu, P., Gupta, V.E., Gupta, R.A., Sung, J., et al. (2018) Real-World Evidence Concerning Clinical and Economic Outcomes of Switching to Insulin Glargine 300 Units/mL vs Other Basal Insulins in Patients with Type 2 Diabetes Using Basal Insulin. Diabetes, Obesity \& Metabolism, 20, 1293-1297. https://doi.org/10.1111/dom.13199

[15] World Medical Association (2013) Declaration of Helsinki: Ethical Principles for Medical Research Involving Human Subjects. JAMA, 310, 2191-2194. https://doi.org/10.1001/jama.2013.281053

[16] Bradley, C. (1999) Diabetes Treatment Satisfaction Questionnaire. Change Version for Use Alongside Status Version Provides Appropriate Solution Where Ceiling Effects Occur. Diabetes Care, 22, 530-532. https://doi.org/10.2337/diacare.22.3.530 
[17] (1999) ICH Harmonised Tripartite Guideline. Statistical Principles for Clinical Trials. International Conference on Harmonisation E9 Expert Working Group. Statistics in Medicine, 18, 1905-1942.

[18] Sherman, R.E., Anderson, S.A., Dal Pan, G.J., Gray, G.W., Gross, T., Hunter, N.L., et al. (2016) Real-World Evidence-What Is It and What Can It Tell Us? The New England Journal of Medicine, 375, 2293-2297. https://doi.org/10.1056/NEJMsb1609216

[19] Ritzel, R., Roussel, R., Bolli, G.B., Vinet, L., Brulle-Wohlhueter, C., Glezer, S., et al. (2015) Patient-Level Meta-Analysis of the EDITION 1, 2 and 3 Studies: Glycaemic Control and Hypoglycaemia with New Insulin Glargine $300 \mathrm{U} / \mathrm{ml}$ versus Glargine $100 \mathrm{U} / \mathrm{ml}$ in People with Type 2 Diabetes. Diabetes, Obesity \& Metabolism, 17, 859-867. https://doi.org/10.1111/dom.12485

[20] Ritzel, R., Roussel, R., Giaccari, A., Vora, J., Brulle-Wohlhueter, C. and Yki-Jarvinen, H. (2018) Better Glycaemic Control and Less Hypoglycaemia with Insulin Glargine 300 U/mL vs Glargine 100 U/mL: 1-Year Patient-Level Meta-Analysis of the EDITION Clinical Studies in People with Type 2 Diabetes. Diabetes, Obesity \& Metabolism, 20, 541-548. https://doi.org/10.1111/dom.13105

[21] Rosenstock, J., Cheng, A., Ritzel, R., Bosnyak, Z., Devisme, C., Cali, A.M.G., et al. (2018) More Similarities than Differences Testing Insulin Glargine 300 Units/mL versus Insulin Degludec 100 Units/mL in Insulin-Naive Type 2 Diabetes: The Randomized Head-to-Head BRIGHT Trial. Diabetes Care, 41, 2147-2154.

https://doi.org/10.2337/dc18-0559 


\section{Appendix}

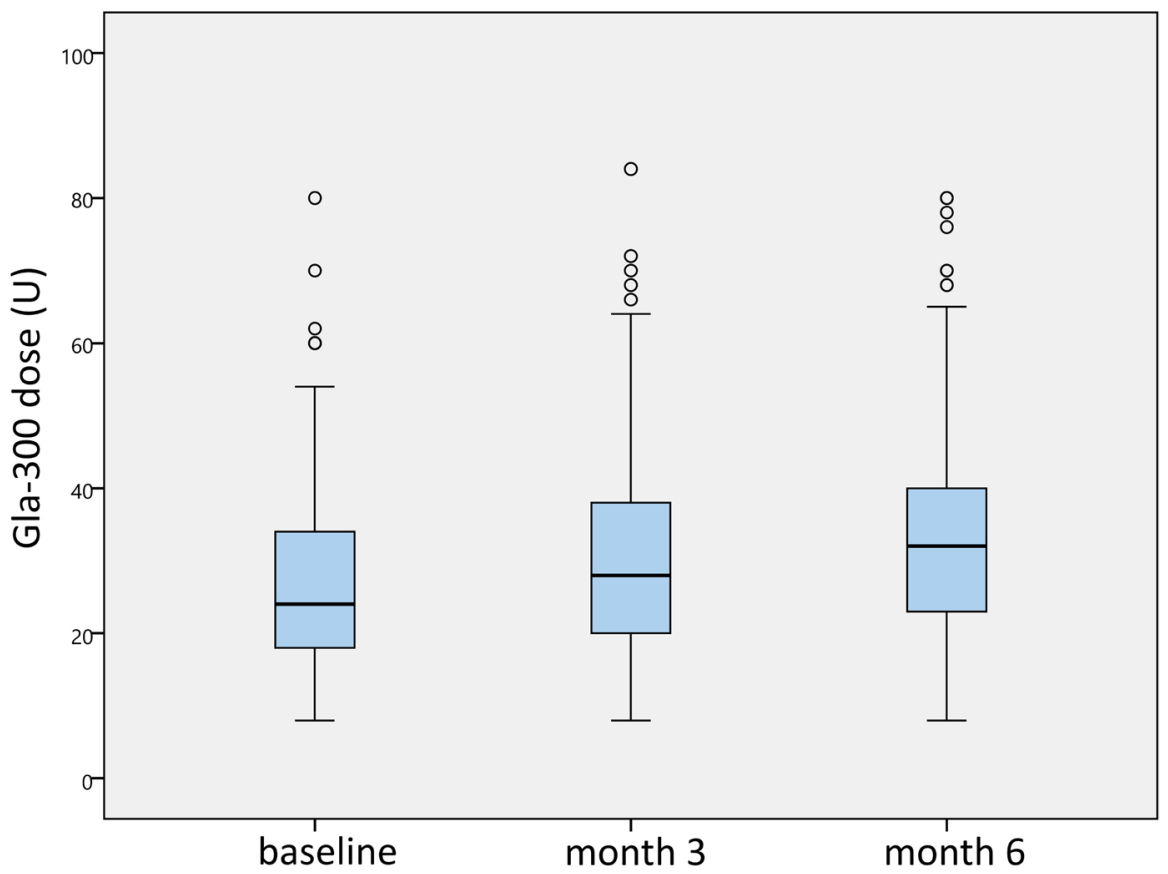

Figure S1. Mean change of daily dose from baseline to month 6 .

Table S1. Basal insulin treatment before initiation of Gla-300.

\begin{tabular}{cccccc}
\hline Types of insulins & $\begin{array}{c}\text { Patients } \\
(\mathbf{n})\end{array}$ & $\begin{array}{c}\text { Patients } \\
(\%)\end{array}$ & $\begin{array}{c}\text { Mean dose } \\
\text { (U) }\end{array}$ & $\begin{array}{c}\text { Median dose } \\
\text { (U) }\end{array}$ & $\begin{array}{c}\text { Administration/ } \\
\text { day }\end{array}$ \\
\hline NPH human insulin & 80 & $26.7 \%$ & 20 & 20 & 1 \\
Insulin glargine $100 \mathrm{U} / \mathrm{ml}$ & 135 & $45.0 \%$ & 29 & 26 & 1 \\
$\quad$ Insulin detemir & 84 & $28.0 \%$ & 24 & 22 & 1 \\
$\quad$ Insulin degludec & 0 & $0.0 \%$ & & & 1 \\
$\begin{array}{c}\text { Other insulin analogue - } \\
\text { Abasaglar }\end{array}$ & 1 & $0.3 \%$ & 16 & 16 & 1 \\
$\quad$ Total & 300 & $100.0 \%$ & 26 & 22 & \\
& & & & & \\
\end{tabular}

